\title{
Two Methods for Learning ALT-J/E Translation Rules from Examples and a Semantic Hicrarchy
}

\author{
Ilussein Alnuallim \\ Info. and Computer Science Dept. \\ King lahd University of \\ Petrolenm and Minerals \\ Dhahran 31261, Saudi Arabia
}

\author{
Yasuhiro Akiba Takefumi Yamazaki \\ Nkio Yokoo Shigeo Kancela \\ N'l'J' Communication Science Labs. \\ 1-2356, Take, Yokosuka-shi \\ Kanagawatken 238-03 \\ Japan
}

\begin{abstract}
This paper presents our work toundrals the automatic: accuisition of transletion rules from Japancese- Linglish translation examples for NT'T's ALT'-J/r' machine translation system. We apply two machine learning algorithrns: Maussler's algorithm for learning internal disjunctive concept and Quinlan's ID3 alyorthm. Whorimental results show that our approach yirlds rales that are highly arcatrate compared to the manulally created rules.
\end{abstract}

\section{Introduction}

A critical issue in AI research is to overeome the knowledge acquisition bottleneck in knowledge- based systems. $\Lambda$ ss a knowledge base is expanded, ardding, more knowledge and fixing previous erroneones knowlelge become increasingly costly. Moreover, maintaining the integrity of large knowledge bases has proven to be a very challenging task.

A widely proposed approach to deal with the knowledge accuisition bottleneck is to employ some learning medhanism to extract the desired knowledge autornatically or semi-autormatically from ac:tual cases or examples [13uchanan \& Wilkins 1993]. The validity of this approach is becoming nore evident as varions machine-learning-hatsed knowledge accquisition tools for real-world demains are being reported [Kim \& Moldovan 1993, l'orter et al. 1990, Sato 1991a, Sato 1991b, Utsuro et al. 1992, Wilkins 1990].

AIS-J/L, which is an experimental JapaneseEnglish translation system developed at Nippon 'Telegraph and 'Telephone Corporation (N'I"I), is one example of a large knowledge-bassed systern in which solutions to the knowledge arcuisition bottenerk are definitely needed. One major component of this system is its huge collection of tratustation roless. Wach of these rules associates a dapanese sentence pattern with an appropriate linglish pattern. To translate a Japanese sentence into linglish, AliT-J/E looks for the mle whose Japaneso pattern matches the sentence best, and then uses the linglish pattern of that rule for translation.

So far, ALC1-d/F translation rules have been composed mannally by extemsively trained human experts. 'To cualify for this job, an expert must not only master both linglish and Japanese, but also be very farniliar with various components of the system. liak h time the rules are expanded or altered, the new set of rales must then be "debugged" neing a collection of test calics. Ustually, several iterations ane needed to arrive at trauslation rules of acepptable quality.

Creating, new trantslation mles as woll as refining; existing ones have proven to be extremely diflicult and time-consmoning because these tasks require considering a huge space of possible combinations (rules in $A[T-3 /[\mathrm{H}$ are expressed in terms of as much as 3000 "semantic categorire"). The high costs involved make the mamual creation of ALI'-J/E's translation rules inpractical. Indeed, in spite of the vast amount. of resources spent, on building the coment rules of ALT'-J/1', faults in these rules are still detected from time to time, making system maintenance a continuous recquirement.

I'he aim of this work is to make $A$ L'l-J/L', translat tion moles less costly and ruere reliatse through the use of inductive marldine learning tednirges. Caresul examination of the mannal process which has been followerl so fiar by AL'T-J/L's experts for building translation rules reveals that most of the eflort is spent on figuring out the condition part of the rules (that is, the Japinese patterns). Therefore, we propose the use of inductive machine learning algorithms to leam these conditions from examples of Japanese sentences and their linglish translations. Under this machine larming approadt, the uscr is redieved from exploring the huge space of alternatives she/he has to consirter when constructing translation rules manually fom scated a joh whel only extensively trained experts can perforn. The task is now turned into a scarch for sorme reasomable mles that explain the given training examples, where the search is handled antomatically by a loming algorithm. This not only 
saves the user's time, but also makes it mmecessary for the user to be an expert of the $A T T-3 / \mathrm{E}$ system. Moreover, this approach significantly reduces the "subjectivity" of the rules since the intervention of human experts is minimized. This is particularly important because the innmense number of translation rules (currently over 10,000$)$ requires employing a team of experts over an extended period of time.

Two learning methods are investigated in this patper. Experiments show that the rules learned by these methods are very close to tho rules manually composed by human experts. In most cases, given a reasonable number of training examples, the enployed methods are able to find rules that are more than $90 \%$ accurate when compared to the mamally composed rules.

The rest of this docurnent is organized as follows. We begin in Section 2 by a brief overview of the ALTJ/E Japanese-Finglish translation system. In Sections 3 , we discuss some of the problems that arise when the translation rules of $A \mathrm{LT}-\mathrm{J} / \mathrm{E}$ are composed manually by human experts. T'hen, we propose in Section 4 an alternative approach based on machine learning techniques. In Section 5, we describe the inductive learning methods used, followed by an experimental evaluation of these methods in Section 6. Finally, conclusion remarks are stated in Section 7.

\section{AlT-J/E: A Brief Overview}

ALT'-J/E, the Automatic Lariguage Translator: Japanese to English, is one of the most advanced and well-recognized systems for translating Japanese to English. It is the largest such system in terrns of the amount of knowledge it comprises. In this work, we are concerned with the following components of the ALP -J/L system:

1. 'The Semantic Ilierarchy,

\section{The Semantic Dictionary, and}

3. The Translation Rules.

We briefly describe each of these components below. For more details about the AJI-J/L systerm, we refer the reader to [Ikehara et al. 1989, Ikehara et al. 1990, Ikehara et al. 1991].

As shown in Figure 1, the Semantic Mierarchy is a sort of concept thesaurus represtented ats a trec structure in which each node is called a semantic cateyory, or a category for simplicity. Edges in this structure represent "is-a" relations among the categories. For example, "Agents" and "J'eople" (see ligure 1) are both categories. The edge between these two categories indicates that any instance of "I'(eple". is also an instance of "Agents". The current version of ALI'J/E's Semantic Hierarchy is 12 levels deere and has about 3000 nodes. The Semantic Dictionary malps: each Japanese noun to its appropriate semantic categories. For example, the Semantic Dictionary states that the noun $\mathrm{g}_{\mathrm{H}}$ (niwatori), which meahs "chicken" or "hen" in Lnglish, is an instance of the categories "Meat" and "Birds".

The Translation Rules in ALI-J/F associate: Japanese patterns with English patterns. Currently, AL'T-J/E uses ronghly 10,000 of these rules. ${ }^{1}$ As Figure 2 shows, each translation rule has a Japanese pattern as its left-hand side and an English pattern ass its right-hand side. For example, the first rule in this figure basically says that if the Japanese verb in a sentence is 㸺く (yaku), its subject is an instance of "People", and its object is an instance of "Bread" or "Cake", then the following English pattern is to be used:

$$
\text { Subject "lakke" Object. }
$$

Note that in this case the Japanese verb the (yaku) is translated into the English verb "bake". 'This same Japunese verl can also be translated into the Luglish verbs "roast", "broil", "cremate" or "burn", depending on the context. These cases are handled by the four other rules given in ligure 2.

Thanslation mles are meant only to handle basic sentences that contain just a single Japanese verb. Such sentences are called "simple sentences." To t.anslate a complex sentence, ALT-J/L does various kinds of pre- and post-processing. Roughly speaking, the given complex sentence is first broken into a collection of sirnple sentences in the pre-processing phase. Then, the linglish translations of these are combined together in the post-processing phase to give the final translation of the complex sentence.

'To trarsslate a simple sentence, ALI-J/E looks for the most appropriate translation mle to nse. Based on the verb of the sentence, the system considers as candidates all those translation rules that have this verb on their left-hand side. The English pattem of the rule whose Japanese pattern matches the ser1tence best is then used to generate the desired English translation.

As shown in Figure 2, the Japanese patterns are expressed using the vatriables $N_{1}, N_{2}, \cdots$, etce, which represent varions components of a lapanese sentence, such as the subject, the object, etc." The "degres of matching" between a Japanese pattern and a semtence is based on how well the values of these variables for the given sentence match those categories required by the Japanese pattern. The Semantic Dic-

\footnotetext{
'Lu fact. Al'l-J/li hats three different kinds of translation rules: (i) the sentatic pattern transfer mles (ronghly 10,000 rules). (ii) the idiomatic expression transfer mues (at)ont 5.000 rules), and (iii) the general tratsfer rules. We nes the term "Trauslation diules" here to refor to the semant ic pattern transfer rules. These form the matjority of the rules, and they ane the nost frepuently used by AJT.J/L.

"Jhe termu "simple sentence" is a libect translation of (ta11)

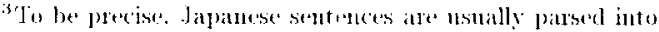

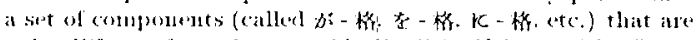
quite different from those nerel in Guglish. Using "subject" and

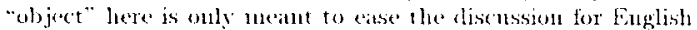
reaklers.
} 


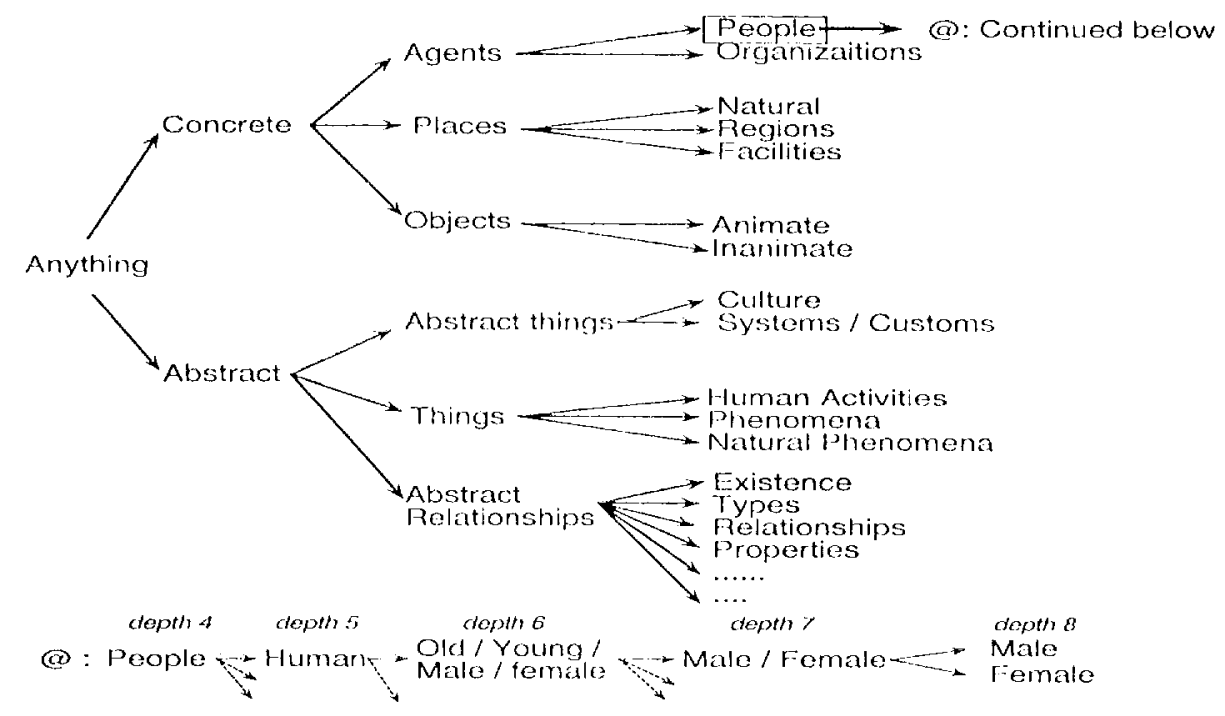

Fignes 1: 'The upper levels of the Semantic Iliemarchy in AL'T'-J/E.

IF'

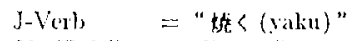

$N_{1}$ (Subj) $\equiv$ "P'ople"

$\mathrm{II}$

$N_{2}(() b j) \equiv "$ "Bread" or "Ciatie"

$$
\begin{aligned}
& J Y^{\prime}(\mathrm{rl})=\text { " } \\
& N_{1}(\operatorname{Sin} b j) \equiv \text { "Popple" }
\end{aligned}
$$

$\mathrm{IF}$

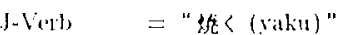

$$
\begin{aligned}
& N_{1} \text { (Subj) "Popplle" } \\
& N_{2}((), j) \quad \Xi \text { "Fint" on "Seratioul }
\end{aligned}
$$

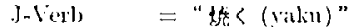

$$
\begin{aligned}
& X_{1}(\text { Sul, j) }=\text { Apents" } \\
& N_{2}\left(() \mathrm{r}_{\mathrm{j}}\right) \quad \equiv \text { "P(o, le" ar "Animallo" } \\
& \text { J-Verb = "kf< (ratki)" }
\end{aligned}
$$

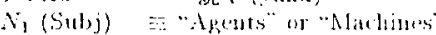

\begin{tabular}{|c|c|c|}
\hline \multirow{2}{*}{$\begin{array}{l}\text { THEN } \\
\text { THLN }\end{array}$} & $\begin{array}{l}\text { Subj } \\
\text { E-Verb } \\
\text { Ol,j }\end{array}$ & $\begin{array}{l}=N_{1} \\
=- \text { bake" } \\
=N_{2}\end{array}$ \\
\hline & $\begin{array}{l}\text { Subj } \\
E-V(t, d) \\
\text { oh,j }\end{array}$ & $\begin{array}{l}=X_{1} \\
=" \text { roilst } \\
=N_{2}\end{array}$ \\
\hline THEN & 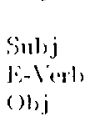 & $\begin{array}{l}=N_{1} \\
=" \text { hrovil" } \\
=N_{2}\end{array}$ \\
\hline THJIN & $\begin{array}{l}\text { Subj } \\
\text { liferb } \\
\text { Obj }\end{array}$ & $\begin{array}{l}=N_{1} \\
=\therefore \text { "monate" } \\
=x_{2}\end{array}$ \\
\hline $1 M$ & $\begin{array}{l}\text { Subj } \\
E-V i+1) \\
(O), j\end{array}$ & $\begin{array}{l}=x_{1} \\
=" b_{\text {uru }} \\
=x_{2}\end{array}$ \\
\hline
\end{tabular}

$$
\begin{aligned}
& N_{2}(01, j) \quad \cong \text { "lactes" or "Ol,jects" an }
\end{aligned}
$$$$
\text { IF }
$$$$
\text { IF }
$$$$
\text { -1.04at ions" }
$$

Figure 2: 'Translation mules for the Japanese verb the (yaku). 'These rules are compesed mamally by human experts. ": " indicates "an instance of". 
tionary is nsed during the matching process to determine whether or not a given noun is an instance of a certain category.

\section{Shortcomings of the Manual Approach}

Translation rules in the ALCL-J/E system have so far been composed manually by human experts. However, due to the high cost-per-rule, and because of the huge number of translation rules needed for $A L Y-J / L$ to carry out a reasonable transiation job, the mamal approach has been concluded by the developers of ALI'J/E to be impractical. In particular, the following problems have been reported:

- Building and maintaining the translation rules require a great deal of expertise. 'To qualify for this task, skillful experts are required not only to master both Japanese and English, but also to be fully familiar with ALT-J/E's large Somantice Hierarchy and to understand the overall process of the systern. Such qualifications are costly and involve extensive training.

- In spite of the vast amount of resources spent, on building the current rules of ALT-J/L by human sexperts, faults are still detected from time to time, malking the maintenance of the system a continnous requirement.

- The manslation rules are not quite concrete ancl vary depending on the expert. Rules constructed by one expert are not easy for another expert to understand and modify. 'This makes the maintenance process more difficolt and makes it hard to substitute an expert by another.

- An important objective is to build specialized versions of ALT. J/E to be used in specific: application domains. The marual approadt is obviously umrealistic since it involves more tmining of the human experts with respect to the target application domain, and becanse this process hats to be repeated for every new domitin.

- One of the problems facing the designers of ALT$\mathrm{J} / \mathrm{E}$ is the refinement of the Semantic Hicrarchy. Whenever this structure is altered, the translation rules must also be revised to reflect the change. Such revision is extrencly tronblesome and errormprone if it is dome mamally.

\section{A. Machine Learning Ap- proach}

'The problems we have just listed regarding the manual construction of $A L \cdot Y-J / E$ 's translation rules are largely solved if the process can be antomated. An attractive approach to this problem is/to resort to inductive machine learning techniques to extract the desired translation rules from examples of Japanese sentences and their English translations. At the current stage, however, learning translation rules fully automatically from examples alone secms to be too challenging. A more realistic goal is to minimize... rather than to totally eliminate - - the intervention of human experts in the rule aquisition process. Thus, our current objective is to concentrate on antomating the most difficult and tine-consmning parts of the mannal procedure.

The goal of the present work is to learn what we call "partial trauslation rules". A partial translation rule consists of the left-hand side along with the Finglish verb of the right-hand side of a translation rule. In other words, the only difference between a translation rule and a partial translation rule is that the latter has only an linglish verb rather than a full binglish pattern as its right-hand side.

Construeting a partial tramslation rule is the most difficult part of constructing a translation ruke. Indeed, turning a partial rule into a complete one is a relatively easy task that can be done by a human operator with moderate knowledge of English and Japanese.

\section{Learning Task and Methods}

In this work, we investigate two different inductive karning algorithms. Before talking about these algorithns, we will first make the learning task more precise and shed some light on the difficulties that distinguish it from other previously studied learning tasks.

\subsection{The Learning Task}

The jol of a learning algorithm in our setting is to construct partial tramslation rules. For a given Japanese verb J-verb and a possible English translation li-verts of that verb, the algersithm has to find the appropriate condition(s) that should hold in the

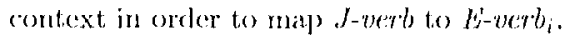

As an example, consider the Japanese verb tide (tsukan). This verb corresponds to the linglish vorbs "nse", "spend" and "employ". 'The choice anong these English verbs depends mostly on the object of the sentence. For exumple, if the object is an instance of "Asset" or "lime", then "spend" is applutepriate. 'Thus, a rough mule for mapping 优 5 (tsukau) to "spend" may look like

$$
\begin{aligned}
& \text { IF J-YERB = 使5 } \\
& \text { and OBjJect in an mostance of "Time" or "Asset"] }
\end{aligned}
$$

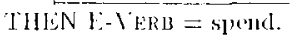

Wo seek to learn this kind of mles from examples of Japanese sentences and their lenglish translations, such as the following pair: 


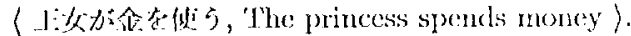

After parsing (which is carried ont by AIT-J/L's parser), the above example gives the following pair:

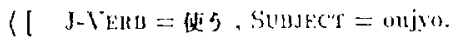
OBJE["I = kane ]. E-TERB = spend )

By looking up the Semantic: Dietionary of ALCL-J/E, the possible semantic categories for onjyo are "Noble I'erson", "Danghter" and "Female", and those for kane are "Asset", "Metal", "Day" and "Nerdal". Thus, this exarnple is fircally given to the leaming algorithm in the following form:

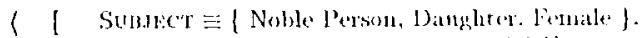

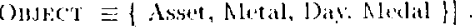
I.-YEIn $=$ spenul $)$.

where $N=S$ indieates that the sentence component $N$ is an instance of ench category s $6 . S$. 'The general format of the training examples is at: follows:

$$
\text { 《[ } \begin{aligned}
N_{1} & \equiv\left\{a_{1}, a_{2}, \cdots\right\}, \\
N_{2} & \equiv\left\{b_{1}, b_{2}, \cdots\right\}, \cdots \\
N_{n} & \left.\equiv\left\{c_{1}, c_{2}, \cdots\right\}\right], b_{-}-V_{e}(b)
\end{aligned}
$$

where each $N_{i}$ represents a component of the sentence (subject, object, etc.), and each $a_{i}, b_{i}$, and $c_{i}$ is a sermantic category.

Forn the viewpoint of machine learning research, the above learning task is interesting/challonging, from two jers]eetives:

- Iluge amount of background knowledge: 'lo' be appropriate for our learning task, the learning algorithrn must effectively utilize AldJ/E's large Semantic Therarchy. This repuirement of being capable of exploiting such a huge amonrt of background knowledge disqualifies most of the known inductive learning alyorithns from directly being used in our domain.

- Ambiguity of the training examples: Unlike most known learring; domains, the training: examples in our setting (as piven in lix. (1)) are ambignews in the sense that each of the variables (Substecr, Obstecr, ete.) is assigned multiple values rather than a single value. loxensing on the relevant values (that is, the values that contributed to the choice of the Finglish verb) is an extra challenge to the learner in our domain.

To deal with the above leaning problem, we investigated two approaches. One is based on a theroretical algorithm introduced by Haussler for learning internal disjunetive concepts, and the other on the well-known II)3 algorithm of Quinlans.

\subsection{Haussler's algorithm for learning internal disjunctive expressions}

In our first apysoakh, we represent the condilions of the learned partial translation rules as internal disjunctive erpressions, and employ an algorithm given by flantisler for leaning concepts expressed in this syntax. Hantssler's algorithn enjoys many advantages. Jirst, it has been analytically proven to be quite effecient both in terms of time and the number of examples needed for learning. Second, the algoritim is capable of explicitly utilizing the background knowledge represented by the Semantic Hierarchy. Noreover, the langlage used by hunam experts

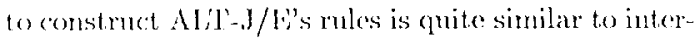
nal clisjumetive expressions, sugeesting the appropriit coness of this algocithm's bias. 1laussler's algorithm, on the other hand, sufler's the important shorteming (within our setting) that it is not capable of learniug from andiguous examples. In order to be able to use the algorithm for on task, the and ignity hats to be explicitly removed from all the traning examples. (of ecourse, this appreach is not desinable because it requires some intervention by a human expert and beranse there are no gratuanteres that clisambignation is done in a perfect manmes.

\subsection{Quinlan's ID3}

Onr second approach is based on the ID3 algorithm introduced by Quinlan in [Quinlan 1986]. As it is, 11)3 is not alle to ntilize the backgronnd knowledge of our domain, nor is it capable of dealing with ambignous traning examples of the form given by licp. (1). It is chearly inappropriate to treat $N_{1}, N_{2} \cdots$ as multivalued variables, which is the most common way of nsing 11)3. 'This is because of the huge number of values these variables can take, and also becanse we need to exploit the background knowledge represented by thee Semantic Ilicerarchy.

Tis be able to use $1 \mathrm{D} 3 \mathrm{3}$ in our clominin, we transform the training examples into a new representation that can be hardlled by II)3. The transformation we propose is dome in a way such that the relevant information from the the Semantice Hierarchy are inchued in the newly represented examples, and, at the same time, these newly represented examples still reflect the ambignily present in the original examples.

Our transformation method is described as follows: lat. $A$ be the set of all the ategeries that appeared in the traning examples, and thejr ancestors. For every " $\epsilon$, we rlefine a binary feature as at test of the form

$$
\text { is } N_{i} \text { ar instance of } c \text { ? }
$$

lor a training exanple

$$
\left\langle\left[N_{1} \cdots S_{1}, \cdots N_{i} \cdots S_{i}, \cdots N_{n}=S_{n}\right],\left[V_{r} V(r b\rangle\right.\right.
$$

we let the ontconte of the above test be true il and only if there exists some $s \in S_{i}$ such that $s$ is an ancestor of $a$ in the Semantic J lienardy, or c itself. Using these features, we convert cach of the trainings, cxamples into a new pair $\left\langle V^{\prime}, l^{\prime}-V e r b\right\rangle$ where $l$ is a vector of bits ach representing the mutcome of the corresponding feature for the given trating example. 
Given the above definition of the binary features, the new pairs $\langle V, E-V e r b\rangle$ include all the necessary background knowledge obtained form the Somantic Hierarchy, and also reflect the ambignity of the original training examples. In other words, the above transformation can be seen as "compiling" the information of the original ambignous training examples along with the necessary parts of the Semantic Hierarchy into a format that is ready to be processed by II)3 (or in fact, by many other feature-based learning algorithms).

Note that if we create a feature for every scmantic category $c$ and every sentence component $N_{i}$, then the total number of features will become infeasibly large (many thousunds). However, what we need is only to consider those categories that appeared in the training data, and their ancestors (the set $A$ above). In our experiments, this results in a reasonable number of features (one to two hundred). This is because the number of exarnples is linnited and also because: of the rather "tilted" distribution of what categories can naturally appear as a certain component of a sentence for a given verb. (Lg. the object of the verb 钦 む (nomu), which roughly means to "drink", can not be just anything!)

The most important advantage of the above approach is that it can be applied to ambignous training exarnples as they are, without the need to remove the ambiguity explicitly as we did with Haussler's algorithm. Another advantage of using ID3 is that we do not need to break our learning task into binary class learning problems since ID3 is capable of learning multi-class learning concepts.

\section{Experimental Work}

The goal of the experiments reported here is to evaluate the quality of the partial translation rules learned by the two learning methods we have just described. The comparison includes the following three settings:

1. Using Haussler's algorithm to learn from training examples after removing the ambiguity.

2. Using ID3 to learn from training examples after removing the ambiguity and performing the transformation given in the Subsection 5.3.

3. Using ID3 to learn from training examples after performing the transformation given in the Subsection 5.3 , but without removing the ambignity.

In a sense, the first setting represents the best, we can do in the absence of the ambiguity since Haussler's algorithm does a good job in exploiting the backgromel knowledge from the Semantic Ilicrarchy. Comparing Setting 2 with Setting 1 tells us how successful om transformation of the training examples is in letting ID3 make use of the available background knowledge. Finally, comparing Setting 3 with Setting 2 tells $1 \mathrm{~s}$ how successful our transformation is in letting ID3 learn directly from anbiguous training examples.

The experiments were done for six diflerent Japanese verbs. Table 1 shows a list of these verbs, along with the number of training examples used, and the accuracy levels obtained by each mothod. In the table, "Lanissler", "ID3-NA" and "ID3 A" renote Setting 1, Setting 2 and Setting 3, respectively. The accuacy was estimated using the leave-one-out crossvalidation method ${ }^{4}$, and assuming that the rules connposed mamually by human experts are perfect (that is, we are measuring how close the learned rules are to those composed mamually).

The performance levels of both llatusslere's algorithm and ID3 when learning from unambignous exanpless are quite sinilar in spite of the fact that each algorithm implements a different bias and has a completely different way of exploiting the backgroumel knowledge. Comparing the performance of ID3 in the two cases of learning from ambiguous and unambignous cxarnples, ambignity is not harmfne to ID'3's performance in most cases. In fart, for some of the verbs, the performance is even better when ambignity is preserte. This suggests that the approach we have chosen to deal with ambiguity is eflective for our task, and that explicit removal of ambignity is not an attractive strategy since it is not easy to do, and since it does not greatly inprove the accuracy anyway.

The rnost important point here is that the observed accuracy of both the ID3 algorithm and Haussler's algoritlun is satisfactorily high overall in spite of the limited number of the training examples used. Such a high level of accuracy strongly indicates that the use of these algorithrns will provide significant aid in the construction of ALC-J/E's translation rules.

\section{Conclusion}

This paper reported onr work towards the aecuisition of Japancese-English translation rules through the use of inductive machine learning techniques. 'Two approaches were investigated. The first approach is based on a theoretically-founded algorithm given by llanssler for learning internal disjunctive concepts. This algorithm has the arlvantage that it is tailored to utilize background knowledge of the kind available in our domain. We found, lowever, no obvious way to make this algorithm learn directly from ambiguons training examples, and thus, ambignity was explicitly removed from the training examples in order to use this atgorithm. Our second approach is based on the II) 3 algerithun. As it, is, ID 3 is not alble to utilize the background knowledge of our domain, nor is it capable of dealing with anbignous training exann-

\footnotetext{
"Exantuph are excheled from the training set one at a tines.

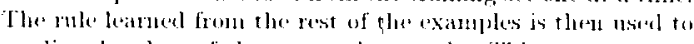
predict the class of the renowed eximple. This wats repaled

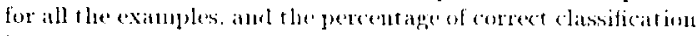
is reprorterl.
} 
Iable 1: Experimental results on six Jajanese verbs. Numbers show the accuracy per-cent, estimated using; the leave-one-ont cross-valinkation methed. 11)3-N.t indicates using 1D)3 with the ambignity removed from the training examples. Il)3 A indicates using 103 to leam from ambignous training examples.

\begin{tabular}{|c|c|c|c|c|c|}
\hline & & No. of & & curacy \% & \\
\hline Jaquanese Verb & Lnglish Verbs & bils. & Ilansiler & II) $3 \mathrm{NA}$ & II) 31 \\
\hline 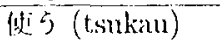 & use, spend, employ & 80 & 85 & 93 & 91 \\
\hline 领吉 (nomm) & chink, take, eat, arcept & 12 & 90 & 98 & 93 \\
\hline 行与 (okonam) & conduct, play, loold & 33 & 9.1 & 88 & 88 \\
\hline 伈じる (onjirn) & answer, enter, neet & 30 & () & 87 & 90 \\
\hline 炒 $<($ yakn $)$ & burn, bike, roast, broil, cremater & 27 & 93 & 89 & 93 \\
\hline$f\left|p^{\prime}\right|<($ toku $)$ & solve, undelo, disipel & 29 & 100 & 100 & 97 \\
\hline \multicolumn{3}{|c|}{ Averalye Accuraty } & 92.0 & 92.5 & 92.0 \\
\hline
\end{tabular}

ples. We gatve, however, an casy way to "compile" the relevant background knowledge along with the ambignous tmaining examples into a modified set of training exarnples on which we were able to directly run ID3. Lixperiments comparing these approachess showed that the rules learned using the seconel approach with the ambignity present, in the training exarmples are almost as accurate as those obtained from atrubignity-free examples using llaussiler's algerithm.

Overall, our experiments showed that using machine learning technigues yields rules that are lighly accurate compared to the mamally created rules. I'hese results suggest that exploiting the reported inductive learning techniques will significantly accelerate the construction process of ALC'-J/E's translation rules. Currently, the reported learning approachess ane being included in a seni-automatic knowledge acousition tool to be nsed in the actual development of the ALI'-J/L system.

Acknowledgement: We wish to thank Dr. S. Ikehara for his continuous encouragement. This work was done while the first anthor was spending a postdoctoral year at N'T'. He also thanks King liahd Unversity of Petroleum and Minerals, Saudi Arabia, for their support.

\section{References}

[Buchanan \& Wilkins 1993] Buchanan, B. (i. and Wilkins, D. C. (Eds.), Readings in knowledge at quisition and learning, Morgan Kaufinann, 1993.

[Haussler 1988] Haumsler, I), "Quantifying inductive bias: Al leaming algorithms and Valiant,'s learning framework", Artificial Intelligene'e, 26(2), 177 221, 1988.

[Ikehara ot al. 1989] Ikehara, S., Miyazaki, M., Shi rai, S. and Yokoo, $\Lambda$. , "An Approarh to Nachine Thanslation Method based on Construetive Pro cess 'Theory", Review of ECl, vol.37, No.1, 39 4.1, 1989.
[Hohara ed al. 1990] Ikchara, S., Shirai, S., Yokoo, A. and Nakaiwa, Il., "lowatrd an M'l' System withont Pre-bditing liffects of New Methods in Al'IJ/1.", Iroc: of MT' Summit-3, 1990.

[lkeharat of al. 1991] lkchara, S., Yokoo, A. ankl Miyazaki, M., "Somantic Analysis Dictionaries for Machine 'Thanslation", (in Japanese), LERCE Report, NLC 91-19, Institute of Electronics, Information and Communication Lingineers, Japant, 1991.

[Kim \& Moldovan 1993] Kim, J. 'T', and Moldovan, D. I., "Accunisition of Semantic: ['atterns for Information Extraction from Corpori", I'rocof CAIA$93,171 \cdot 176,1993$.

[Porter et al. 1990] P'orter, B. W., Bareiss, R., and Ifolte, R. C. Concept learning and heuristic clatssification in weak-theory domains. Artificial Intelligence, $15(3): 229) 263,1990$.

[Quinlan 1986] Qninlan, J. R. "Induction of Decision Trees", Machine: Le arning, 1(1):81-106, 1986.

[Salo 1991a] Sato, S., "MIT'IL: Lxample-Based Word Selection" (in Jaynanese), Journal of Japranese Socictly for Artificial Intelligence, vol.6, No.4, 1991.

[Satce 19916] Siato, S., "NII'T"2: A methorl for Combining laggments of lixamples in lixample-13atsed Thanslation" (in Japanese), Jourral of Japancese Soriety for Artificiul Intelligence, vol.6, No.6, 1991.

[Utsuro et al. 1992] Utsuro, I', Matsumoto, Y. and Natgao, M. "Iexical Knowledge Acequisition from Bilingual Corpora", Proce of the thth Intermetional Conference on Computational Linguistics, $581587,1992$.

[Wilkins 1990] Wilkins, D. C. Knowledge base refinement as improving an incomplete and incorrect domain theory. In Korlratofl, Y. and Michalski, R. S.,

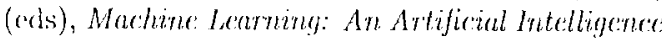
Approuch, vol. 111, pp 493 514, Norgan-Kanfmanu P'ublishers, 1990. 